\title{
Effect of Fired Ag Electrodes on Electrical Properties of a $\mathrm{Pb}\left[\left(\mathrm{Zn}_{1 / 3} \mathrm{Nb}_{2 / 3}\right)_{0.91} \mathrm{Ti}_{0.09}\right] \mathrm{O}_{3}$ Single Crystal
}

\author{
Kouichi HARADA, Senji SHIMANUKI, Shiroh SAITOH and Yohachi YAMASHITA \\ Materials and Devices Research Laboratories, Toshiba Research \& Development Center, Toshiba Corporation, \\ 70, Yanagi-cho, Saiwai-ku, Kawasaki-shi 210
}

\section{$\mathrm{Pb}\left[\left(\mathrm{Zn}_{1 / 3} \mathrm{Nb}_{2 / 3}\right)_{0.91} \mathrm{Ti}_{0.09}\right] \mathrm{O}_{3}$ 単結晶の電気特性に及ぼす焼き付け銀電極の影響 原田耕一・嶋貫専治・斎藤史郎・山下洋八 \\ (株)東芝研究開発センター材料デバイス研究所, 210 神奈川県川崎市幸区柳町 70}

\begin{abstract}
The dielectric constants and electromechanical coupling coefficients of $\mathrm{Pb}\left[\left(\mathrm{Zn}_{1 / 3} \mathrm{Nb}_{2 / 3}\right)_{0.91} \mathrm{Ti}_{0.09}\right] \mathrm{O}_{3}$ (PZNT91/9) single crystals with different electrode materials have been investigated. Two types of electrodes, sputtered Au/Ti and fired Ag, were applied to single crystals of PZNT91/9. The dielectric constant $K$ at room temperature was 8000 for samples with $\mathrm{Au} / \mathrm{Ti}$ electrodes. However, the sample with fired $\mathrm{Ag}$ electrodes had a lower $K$ value of 1000 . After electrical poling, the sample with Au/Ti electrodes had an electromechanical coupling coefficient $k_{\mathrm{t}}$ of $52.7 \%$, while the sample with fired Ag electrodes showed a relatively high $k_{\mathrm{t}}$ value of $61.4 \%$. This could be the result of the large amount of mechanical stress in the fired Ag electrode. Spontaneous intrinsic polarization of the rhombohedral system may be reoriented parallel or antiparallel along one particular direction because of the mechanical stress.
\end{abstract}

[Received December 20, 1996; Accepted September 19, 1997]

Key-words : Single crystal, Perovskite, Fired electrode, Electromechanical coupling coefficient

\section{Introduction}

Lead-based ferroelectric perovskite compounds with the general formula $\mathrm{Pb}\left(\mathrm{B}^{\prime} \mathrm{B}^{\prime \prime}\right) \mathrm{O}_{3}$ are applicable for use in capacitors, electrostrictive actuators and generators. The solid solutions of lead zinc niobate, $\mathrm{Pb}\left(\mathrm{Zn}_{1 / 3} \mathrm{Nb}_{2 / 3}\right) \mathrm{O}_{3}$ $(\mathrm{PZN})$ and lead titanate, $\mathrm{PbTiO}_{3}(\mathrm{PT})$, have a morphotropic phase boundary (MPB) near $9 \mathrm{~mol} \% \mathrm{PT}$. The electrical properties of PZNT91/9 single crystals were reported by Kuwata et al. in 1982.1) The (001) plane crystal has an exceptionally large piezoelectric constant $\left(d_{33}>1500\right.$ $\mathrm{pC} / \mathrm{N})$ and electromechanical coupling coefficient $\left(k_{33}\right.$ $>92 \%)$. Thus, these single crystals are expected to be applicable for use in high-quality ultrasonic transducers as replacements for conventional $\mathrm{Pb}(\mathrm{Zr}, \mathrm{Ti}) \mathrm{O}_{3}$ ( $\left.\mathrm{PZT}\right)$ ceramics. However, these excellent piezoelectric properties were measured using sputtered electrodes. Fired Ag electrodes are used for PZT ceramics due to their excellent soldering properties, reasonable cost and high reliability. However, the effects of fired Ag electrodes on the physical and electrical properties of PZNT91/9 single crystals have not been studied so far. The purpose of this study is to investigate the dielectric and electromechanical properties of PZNT91/9 single crystals with fired Ag electrodes along with those of sputtered $\mathrm{Au} / \mathrm{Ti}$ electrodes.

\section{Experimental details}

The PZNT91/9 single crystals were prepared by the $\mathrm{PbO}$ flux method. ${ }^{1)}$ The raw powders of $\mathrm{PbO}, \mathrm{ZnO}, \mathrm{Nb}_{2} \mathrm{O}_{5}$ and $\mathrm{TiO}_{2}$ were mixed with a pestle and mortar, and the resulting mixture was calcined at $800^{\circ} \mathrm{C}$ for $2 \mathrm{~h}$ in an $\mathrm{Al}_{2} \mathrm{O}_{3}$ sagger. The calcined powders were mixed with $6 \%$ PVA. solution. The result was pressed at $9.8 \times 10^{7} \mathrm{~N} / \mathrm{m}^{2}$ to produce pellets $37 \mathrm{~mm}$ in diameter and $10 \mathrm{~mm}$ thick. The pellets were sintered at $1000^{\circ} \mathrm{C}$ for $4 \mathrm{~h}$ in a dense $\mathrm{MgO}$ crucible. A $55 \mathrm{~mol} \%$ PZNT91/9 sintered pellet and $45 \mathrm{~mol} \%$ $\mathrm{PbO}$ flux were placed in a $100 \mathrm{ml} \mathrm{Pt}$ crucible. The Pt crucible was heated to $1250^{\circ} \mathrm{C}$ for $4 \mathrm{~h}$ and then cooled to $900^{\circ} \mathrm{C}$ at $0.5^{\circ} \mathrm{C} / \mathrm{h}$. The crucible was then air-quenched to room temperature over approximately $24 \mathrm{~h}$. The resulting PZNT91/9 single crystals were rhombohedral. The crystals were cut along the pseudo-cubic (001) plane ${ }^{1)}$ after the orientation was determined with a Laue X-ray diffraction pattern. The obtained wafer size was approximately $15 \times 15 \times 0.5 \mathrm{~mm}^{3}$. Thin films of Au/Ti $(=200 \mathrm{~nm} / 50 \mathrm{~nm})$ were formed by sputtering. This wafer was cut into samples $4 \times 4 \times 0.4 \mathrm{~mm}^{3}$ with a dicing saw (Disco, DAD$2 \mathrm{H} / 6 \mathrm{~T}$ ). After measuring the dielectric properties as a function of temperature increase, the samples were immersed in silicone oil and poled in a $1 \mathrm{kV} / \mathrm{mm}$ electric field. The electric field was applied at a temperature of $200^{\circ} \mathrm{C}$ for $15 \mathrm{~min}$, and the samples were then cooled to $30^{\circ} \mathrm{C}$ in the electric field for approximately $3 \mathrm{~h}$. The electromechanical coupling coefficient, $k_{\mathrm{t}}$, was measured using an impedance analyzer (HP-4195A; network mode) by the resonance and antiresonance frequency methods. The $\mathrm{Au} / \mathrm{Ti}$ electrodes were then removed with \#4000 sand paper. Commercially available Ag electrode paste (Shoei Chemical Co., Tokyo; H4190) was adhered to the samples by a screen printing method and then fired in air at $700^{\circ} \mathrm{C}$ for $5 \mathrm{~min}$. The thickness of the Ag electrodes was 13 microns. After applying the $\mathrm{Ag}$ electrodes, the above process of dielectric measurement, poling and piezoelectric measurement was carried out. The microstructure of the cross section and the surface of the fired Ag samples was observed using a scanning electron microscope (SEM; JEOL JSM-T20).

\section{Results and discussion}

3.1 Microstructure and dielectric properties

Figure 1 (a) shows a cross section of a PZNT91/9 sample with an $\mathrm{Au} / \mathrm{Ti}$ electrode and, (b), with an $\mathrm{Ag}$ electrode. No additional phase ${ }^{2)}$ (such as pyrochlore or glass) is observed at the boundary of either sample between the electrode and the single crystal. Figure 2 shows the temperature dependence of dielectric constants and dissipation factors of samples with $\mathrm{Au} / \mathrm{Ti}$ sputtered electrodes and with $\mathrm{Ag}$ electrodes after removal of the Au/Ti electrodes. Both the dielectric constant and the dissipation factor of the $\mathrm{Au} / \mathrm{Ti}$ sputtered sample showed an anomaly at approximately $80^{\circ} \mathrm{C}$ (denoted as $T_{\mathrm{FR}}$ hereinafter), which corresponds to the rhombohedral-tetragonal phase change. The dielectric 

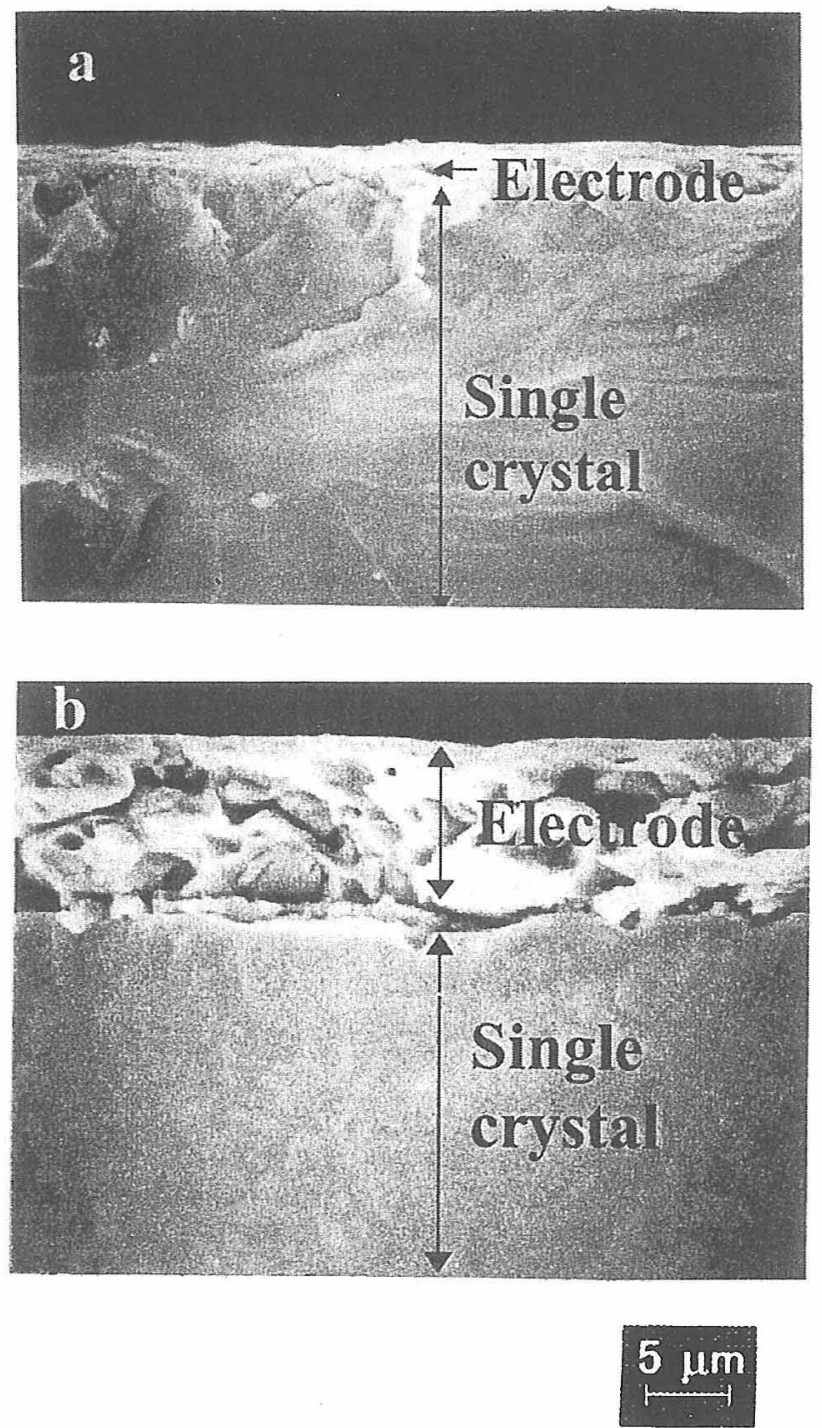

Fig. 1. Cross section of the boundary area between (a) PZNT91/9 single crystal and Au/Ti electrode, and (b) between PZNT91/9 single crystal and Ag electrode.

constant of a sample with Ag electrodes decreases rapidly below the Curie temperature, $T_{\mathrm{C}}$. Simultaneously, the dissipation factor increases from $T_{\mathrm{FR}}$ to $T_{\mathrm{C}}$. These phenomena were found to be very similar to the behavior of $\mathrm{BaTiO}_{3}$ (BT), ${ }^{3)}$ and the discussion of the mechanism behind this behavior follows.

3.2 Mechanism of dielectric constant decrease

The decrease in the dielectric constant of PZNT91/9 with $\mathrm{Ag}$ electrodes is very similar to that of a thermally poled BT single crystal. ${ }^{3)}$ The dielectric constant of $\mathrm{PT}^{4)}$ or $\mathrm{BT}^{3)}$ decreases when the proportion of the $90^{\circ}$ domain is reduced by mechanical detwining ${ }^{4)}$ (or thermal poling ${ }^{3)}$ ); we refer to mechanical detwining ${ }^{4)}$ as "mechanical poling ${ }^{5)}$ " in this paper. As a result of the mechanical poling, the proportion of the $180^{\circ}$ domain increases. In other words, the ferroelectric phase of the ferroelectric material exhibits a very small dielectric constant as a result of the reduced $90^{\circ}$-domain. The decrease in dielectric constant of PZNT91/9 can be attributed to the same mechanism that is proposed for PT and BT. In PZNT91/9, mechanical poling is also expected to cause a decrease in the domains other than $180^{\circ}$. The Ag electrode shrinks to approximately $80 \%$ of its initial length, $64 \%$ of its initial area and $50 \%$ of its initial volume because the $\mathrm{Ag}$ paste is designed to correspond to
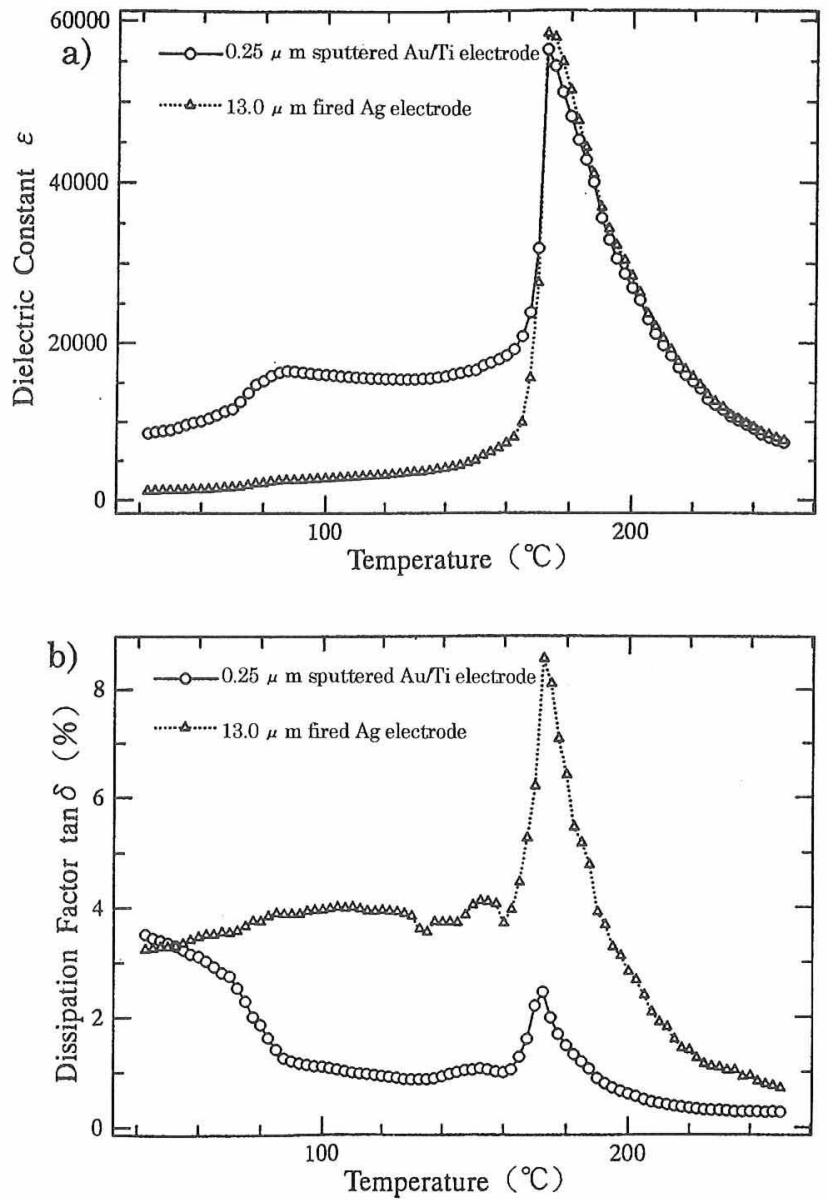

Fig. 2. Temperature dependence of (a) dielectric constant and (b) dissipation factor of PZNT91/9 single crystals with sputtered $\mathrm{Au} / \mathrm{Ti}$ electrodes and fired $\mathrm{Ag}$ electrodes.

the amount of linear sintering shrinkage of approximately $80 \%$ for conventional ceramics. Consequently, single crystal samples were under compressive stress after the Ag electrodes were fired.

Because of the rhombohedral symmetry of PZNT91/9, there are four kinds of equivalent [111] polar directions (eight directions if polarities are accounted for) to which the polarization can spontaneously orient. ${ }^{6)}$ In the present case, the compressive stress forced the spontaneous polarization to rotate or reorient parallel or antiparallel along one particular direction. Accordingly, the amount of $71^{\circ}\left(109^{\circ}\right)$-domains was decreased and $180^{\circ}$-domains became predominant.

The dielectric constant falls as a result of the decrease in the amount of $71^{\circ}$ domain. However, no phase transition is observed at $T_{\mathrm{FR}}$. If such a phase transition occurred, the dielectric constant would have increased at $T_{\mathrm{FR}},{ }^{7)}$ accompanied by a decrease in the dissipation factor. The experimental result shows that there is no phase transition to tetragonal at $T_{\mathrm{FR}}$, which may be due to inner stresses that are caused by $\mathrm{Ag}$ electrodes. In other words, it can be assumed that $T_{\mathrm{FR}}$ and $T_{\mathrm{C}}$ coincide at this level of stress. Therefore, the dissipation factor peak (at $T_{\mathrm{C}}$ ) increases compared with that of the $\mathrm{Au} / \mathrm{Ti}$ sputtered sample. The dielectric constant also increases slightly at $T_{\mathrm{C}}$.

The present mechanism has been deduced only from changes in the dielectric constant and the dissipation factor. A clearer mechanism will be proposed in the future.

3.3 Electromechanical coupling factor, $k_{\mathrm{t}}$

For mechanically poled PZNT91/9 with $\mathrm{Ag}$ electrodes, 
Table 1. Comparison of PZNT91/9 with Fired Ag Electrodes and $\mathrm{Au} / \mathrm{Ti}$ Sputtered Electrodes

\begin{tabular}{|c|c|c|}
\hline & $\begin{array}{l}\text { fired Ag } \\
\text { electrodes }\end{array}$ & $\begin{array}{c}\text { sputtered } \mathrm{Au} / \mathrm{Ti} \\
\text { electrodes }\end{array}$ \\
\hline thickness $(\mu \mathrm{m})$ & 13 & 0.25 \\
\hline $\begin{array}{l}\text { dielectric constant } \\
@ 20^{\circ} \mathrm{C}\end{array}$ & 1000 & 8000 \\
\hline $\begin{array}{l}\text { dielectric constant } \\
\text { @Curie temp. }\end{array}$ & 59000 & 59000 \\
\hline $\begin{array}{l}\text { dissipation factor } \\
@ 20^{\circ} \mathrm{C} \quad(\%)\end{array}$ & 3.0 & 4.0 \\
\hline $\begin{array}{l}\text { dissipation factor } \\
@ \text { Curie temp. (\%) }\end{array}$ & 8.3 & 2.2 \\
\hline $\begin{array}{l}\text { electromechanical } \\
\text { coupling coefficient, } \\
\mathrm{k}_{\mathrm{t}}(\%)\end{array}$ & 61.4 & 52.7 \\
\hline
\end{tabular}

electrical poling is easier than with the $\mathrm{Au} / \mathrm{Ti}$ sputtered electrodes because the $180^{\circ}$ domain, which more mobile than the $71^{\circ}$ domain, is already predominant.

Table 1 and Fig. 3 show $k_{\mathrm{t}}$ values for samples with $\mathrm{Ag}$ electrodes and sputtered electrodes. Samples with fired $\mathrm{Ag}$ electrodes have a much larger $k_{\mathrm{t}}(=61.4 \%)$ than those of the samples with sputtered Au/Ti electrodes (=52.7\%).

\section{Summary}

Two types of electrodes, sputtered $\mathrm{Au} / \mathrm{Ti}$ and fired $\mathrm{Ag}$, were applied to $\mathrm{Pb}\left[\left(\mathrm{Zn}_{1 / 3} \mathrm{Nb}_{2 / 3}\right)_{0.91} \mathrm{Ti}_{0.09}\right] \mathrm{O}_{3}$ (PZNT91/9) single crystals and showed the results obtained below. These results suggest at a new method for controlling the domain structure and electrical properties of these crystals.

(1) The dielectric constant $K$ at room temperature is 8000 for $\mathrm{Au} / \mathrm{Ti}$ electrode samples. However, samples with fired $\mathrm{Ag}$ electrodes indicate the lower $K$ value of 1000 .

(2) The dielectric constant $K_{\max }$ at the Curie temperature is almost the same for both types of electrodes.

(3) After electrical poling, Au/Ti samples indicate an electromechanical coupling coefficient $k_{\mathrm{t}}$ of $52.7 \%$, while samples with fired $\mathrm{Ag}$ electrodes have a relatively high $k_{\mathrm{t}}$ value of $61.4 \%$.

(4) The lower dielectric constant in the case of the fired $\mathrm{Ag}$ electrodes may be due to mechanical poling. This phenomenon increases the mechanical coupling factor $k_{\mathrm{t}}$ of

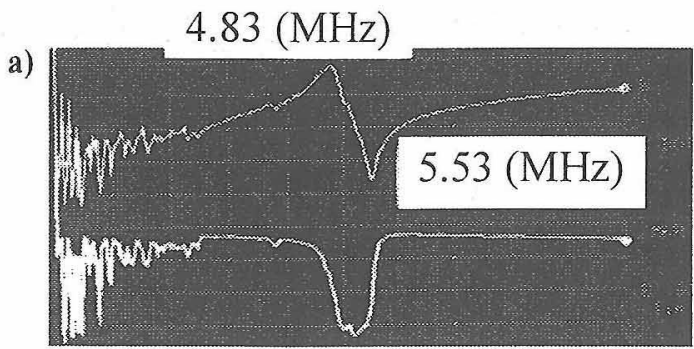

b)

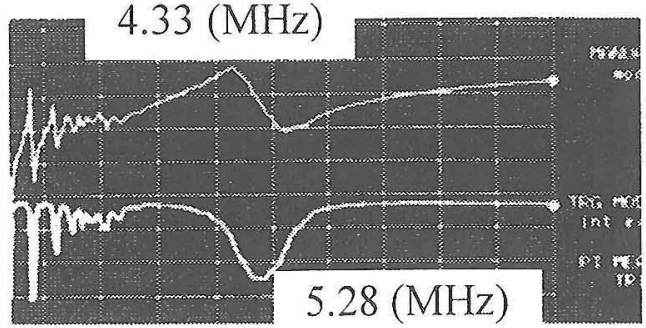

$$
\begin{aligned}
& \mathrm{k}_{\mathrm{t}}{ }^{2}=0.405 \mathrm{f}_{\mathrm{r}} /\left(\mathrm{f}_{\mathrm{a}}-\mathrm{f}_{\mathrm{r}}\right)+0.810 \\
& \mathrm{f}_{\mathrm{r}}: \text { resonance frequency } \\
& \mathrm{f}_{\mathrm{a} \text { :anti-resonance frequency }} \\
& \text { a) } \mathrm{k}_{\mathrm{t}}=52.7(\%) \quad \Delta \mathrm{f}=0.70(\mathrm{MHz}) \\
& \text { b) } \mathrm{k}_{\mathrm{t}}=61.4(\%) \quad \Delta \mathrm{f}=0.95(\mathrm{MHz}) \\
& \Delta \mathrm{f}=\mathrm{f}_{\mathrm{a}}-\mathrm{f}_{\mathrm{r}}
\end{aligned}
$$

Fig. 3. Impedance properties of PZNT91/9 with (a) sputtered $\mathrm{Au} / \mathrm{Ti}$ electrodes and (b) fired Ag electrodes.

poled single crystals.

\section{References}

1) J. Kuwata, K. Uchino and S. Nomura, Jpn. J. Appl. Phys., 21, 1298-302 (1982).

2) H. M. Jang, S. H. Oh and J. H. Moon, J. Am. Ceram. Soc., 75, 82-88 (1992).

3) Z. Chen, K. Yamamoto, M. Adachi and T. Shiosaki, Proceedings of Committee of Japan Technology Transfers Associations, Tokyo, Japan, V26-109 (1995) pp. 1-7.

4) K. Kakuta, T. Tsurumi and T. Fukunaga, Jpn. J. Appl. Phys., 34, 5341-45 (1995).

5) K. Kakuta, "Dielectric Property and Growth of $\mathrm{PbTiO}_{3}$," Master Thesis, Tokyo Institute of Technology (1994).

6) T. R. Shrout, " Novel Ultrasonic Transducer Materials," Medical Ultrasonic Transducer Engineering Workshop, Pennsylvania State University, USA (August 16-18, 1995).

7) K. Uchino, "Elementary Electrical Properties for Ceramists," Uchida Rokakuho, Tokyo (1990) (in Japanese). 